\title{
PROPOSTA DE INTEGRAÇÃO ENTRE MÉTODOS PARA PLANEJAMENTO E CONTROLE DA QUALIDADE
}

\section{PROPOSAL OF INTEGRATION AMONG METHODS FOR QUALITY PLANNING AND CONTROL}

\author{
Marcelo Giroto Rebelato; ;osé Márcio Ramos Fernandes ${ }^{2}$; Andréia Marize Rodrigues ${ }^{3}$ \\ ${ }^{1}$ Universidade Estadual Paulista - UNESP - Jaboticabal - Brasil mgiroto@,fcav.unesp.br \\ ${ }^{2}$ Robert Bosch - Curitiba - Brasil Jose.Fernandes@br.bosch.com \\ ${ }^{3}$ Universidade Estadual Paulista - UNESP - Jaboticabal - Brasil andreiamarize@,fcav.unesp.br
}

\begin{abstract}
Resumo
Nos dias atuais, a maioria das organizações que aplica os diferentes métodos voltados à gestão da qualidade não consegue entender como eles podem trabalhar de forma integrada. A falta de continuidade e integração na aplicação dos métodos da qualidade dificulta a ação gerencial e as empresas que não trabalham para reparar esta lacuna operam, inevitavelmente, um gerenciamento fragmentado. Este artigo tem o objetivo de identificar e explorar a integração entre métodos voltados ao planejamento e ao controle da qualidade. Selecionou-se, da literatura especializada, os seguintes métodos dentro de cada área citada: Desdobramento da Função Qualidade (Quality Function Deployment, QFD) e Análise de Modos e Efeitos de Falhas (Failure Mode and Effect Analysis, FMEA) no planejamento da qualidade; Plano de Controle (Process Quality Plan, PQP), Inspeções, Auditorias de Produto, Controle Estatístico do Processo (CEP) e Método QC Story como método de solução de problemas - no controle da qualidade.
\end{abstract}

Palavras-chave: planejamento da qualidade; controle da qualidade; integração entre métodos da qualidade.

\section{Introdução}

A gestão da qualidade, que pode ser vista ao mesmo tempo como uma função gerencial, uma disciplina acadêmica e uma área de pesquisa e desenvolvimento vem passando, desde o início do século passado, por contínuos e gradativos aprimoramentos no tocante ao direcionamento da ação gerencial. Especialmente depois da II Grande Guerra, especialistas, organizações e governos têm se empenhado em criar métodos aplicados ao planejamento, medição, monitoramento, análise, controle e melhoria da qualidade.

É certo que a incorporação gradual dos métodos gerenciais (a maioria vindos do Japão e dos EUA) pelas empresas de todo o globo, constituiu uma verdadeira revolução na gestão da qualidade. 
Uma revolução silenciosa, cujos resultados palpáveis estão incorporados à criatividade, ao dinamismo gerencial e ao desempenho dos inúmeros produtos ofertados (MOURA, 1994).

$\mathrm{O}$ arcabouço de métodos da qualidade atualmente disponíveis aos gestores dessa área é bastante rico e variado. Para qualquer um dos processos da gestão da qualidade pode-se encontrar uma ferramenta útil ao gestor. O que deve ser enfatizado, entretanto, é que a maioria das organizações que aplica essas "iniciativas da qualidade" não consegue tocar num importante pontochave: como olhar cada uma delas em foco e ao mesmo tempo visualizar o todo e entender como elas podem trabalhar em harmonia (FERNANDES, 2005).

A falta de continuidade e dinamismo interativo na aplicação dos métodos da qualidade pelas empresas é uma realidade. Uma explicação para isso reside no fato de que cada método ou ferramenta foi criado ao seu tempo, por uma organização específica (ou especialista distinto), que tinha um problema gerencial pontual e o objetivo de saná-lo. Dessa forma, os métodos não contêm interfaces previstas de aplicação com outros métodos. O que é relevante, porém, é que a falta de integração dificulta a ação gerencial.

No dia-a-dia da gestão da qualidade, as empresas que não conseguem visualizar as lacunas de integração que existem na grande variedade de métodos a serem aplicados, e não trabalham para repará-las, operam inevitavelmente um gerenciamento fragmentado (KELLER, 2003). Esta fragmentação gerencial ocorre na medida em que o treinamento prepara os funcionários para a aplicação pontual dos procedimentos, técnicas e métodos, porém não os ensina como "costurá-los" vantajosamente. Devido à falta de visão sistêmica, à complexidade do sistema implantado, e talvez para muitos, devido à natureza intrincada dos próprios métodos, são raros os funcionários com capacidade e visão suficientes para garantir que as inter-relações aconteçam na prática (FERNANDES, 2005).

A fragmentação também pode ser explicada pelo fato das normas da qualidade não valorizarem as integrações. Normas para sistemas de gestão da qualidade como a ISO 9000 (ISO 9001:2000, 2000) e sistemas genéricos propostos para a qualidade como o Quality Operating System (KELLER, 2003) têm a característica de serem generalistas, focando na base do sistema da qualidade e nos requisitos elementares necessários. Estas propostas, se por um lado são mais específicas, fornecendo diretrizes, meios para a dirigibilidade e controle, por outro, são falhas em não trazerem consigo procedimentos integrativos e ferramentas "de interface". A maioria das normas da qualidade trata os requisitos de uma forma individual, sem valorizar o conjunto. Estruturas normativas voltadas à indústria automobilística como a ISO/TS 16494 (ISO/TS 16494, 2002), evolução da QS 9000 (CHRYSLER et al, 1998), ou VDA6 (AUTOMOBILINDUSTRIE, 1998) são mais específicas e focam não somente na base, mas se preocupam com detalhes importantes do sistema da qualidade. Apresentam requisitos bastante específicos e trazem consigo a 
exigência do uso de métodos mais avançados da qualidade, como a Análise de Modos e Efeitos de Falhas (FMEA). Contudo, estas propostas, bem como as ferramentas nelas presentes, geralmente são ineficazes na integração entre os processos, tratando o sistema da qualidade como um conjunto de requisitos distintos entre si e não visualizando o todo.

A necessidade da integração e visão sistêmica nos processos da gestão da qualidade se torna mais evidente em contextos em que a gestão da qualidade exija altos níveis de desempenho, como por exemplo, na indústria automotiva, aeronáutica e microeletrônica. São estas áreas de negócios em que o "zero defeito" (CROSBY, 1994) deixou de ser apenas um programa motivacional e passou a ser uma meta alcançável.

Frente à problemática apresentada, este trabalho tem como objetivo identificar e explorar as interfaces entre métodos voltados ao planejamento e ao controle da qualidade, mostrando como estes métodos podem se concatenar efetivamente.

\section{Metodologia de desenvolvimento}

Conforme Cervo e Bervian (2002), as pesquisas podem ser classificadas pela sua natureza, sua forma de abordagem, pelo caráter do objetivo e dos procedimentos técnicos. Quanto à sua natureza, este é um trabalho aplicado, isto é, tem os conhecimentos gerados aplicáveis em um problema prático. Quanto à forma de abordagem, pode-se classificar este trabalho como qualitativo, pois as avaliações e discussões são subjetivas e baseadas na interpretação dos fatos. No tocante ao objetivo, este pode ser classificado como exploratório, pois, a partir da exploração das interfaces entre os métodos da qualidade, propõe-se a integração destes. Em relação aos procedimentos técnicos, esta é uma pesquisa bibliográfica. Para o alcance do objetivo traçado, seguiram-se as seguintes etapas de desenvolvimento:

a) Determinação da abrangência da abordagem integrativa. Aqui, tomou-se como linha de contorno da proposta duas áreas de importância cruciais à gestão da qualidade: o planejamento da qualidade e o controle da qualidade;

b) Determinação dos métodos a serem integrados. Com vistas ao trabalho de integração, selecionou-se dois métodos que, segundo Fernandes (2005), são os mais úteis, mais utilizados e de eficácia comprovada dentro do planejamento da qualidade: o Desdobramento da Função Qualidade (Quality Function Deployment, QFD) e a Análise de Modos e Efeitos de Falhas (Failure Mode and Effect Analysis, FMEA). No controle da qualidade foram selecionados cinco métodos de acordo com a proposta de Juran (2002): Plano de Controle (Process Quality Plan, PQP), Inspeções, Auditorias de Produto, Controle Estatístico do Processo (CEP), e métodos de solução de problemas. 
Estes métodos estão destacados na figura 1, evidenciando suas posições seqüenciais de aplicação (fluxo) no controle da qualidade. Dentro dos diversos métodos de solução de problemas disponíveis, selecionou-se Método QC Story, dada sua simplicidade e popularidade no meio acadêmico e empresarial;

c) Identificação e análise da integração entre os métodos. Esta análise foi conduzida com base na lógica de concatenação entre os requisitos de entrada de cada método e suas saídas. As interfaces são exploradas em partes para, em seguida, formular-se a integração completa entre os métodos destacados.

Figura 1 - Fluxograma do controle da qualidade

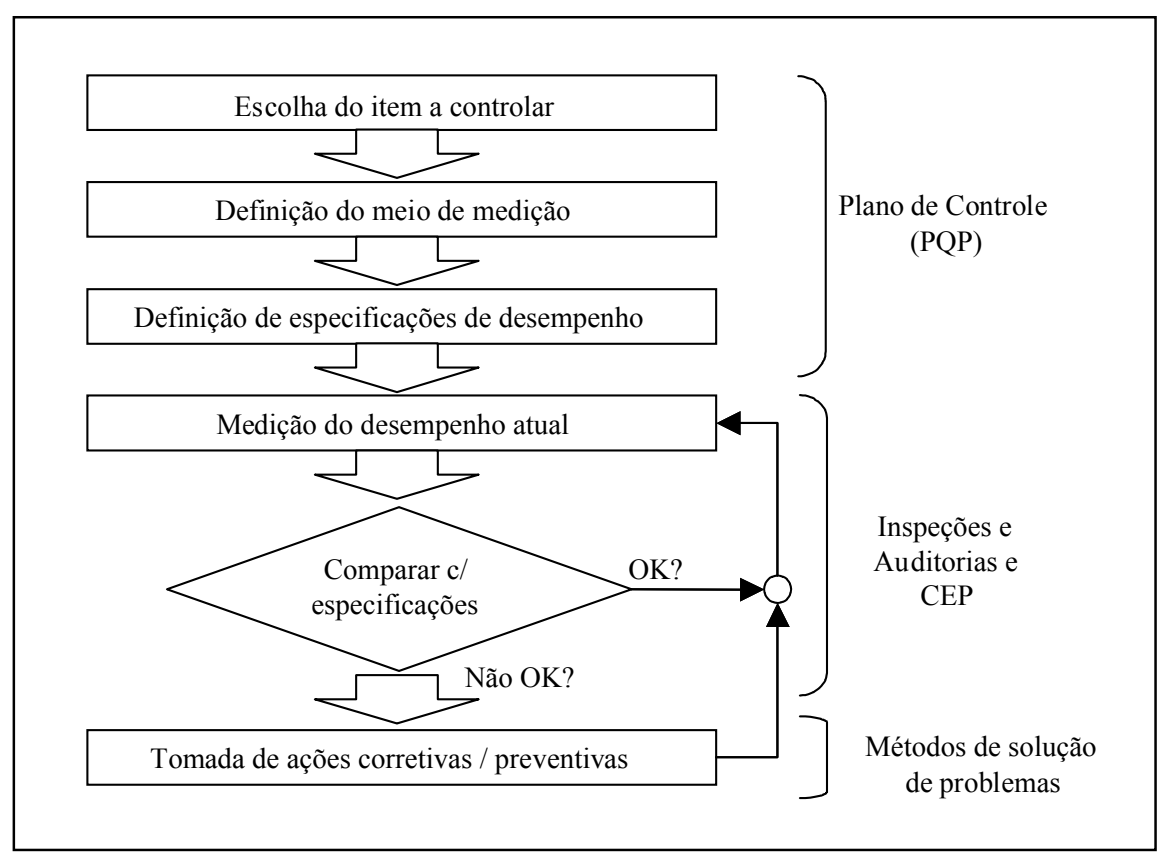

Fonte: Juran (2000, p.2.5)

O artigo segue a estratégia de ordenamento da exposição de cada método segundo uma seqüência lógica de aplicação, partindo-se do planejamento da qualidade em direção ao controle da qualidade. Explora-se cada método de maneira sucinta. Conforme a conveniência de apresentação identifica-se, dentro dos tópicos, as integrações entre dois ou mais métodos. Inicia-se com a integração entre o QFD e FMEA. Em seguida, apresenta-se a integração entre o PQP e o FMEA. Depois, a integração entre quatro métodos: Inspeções, Auditorias de Produto, PQP e FMEA. O próximo passo é mostrar a integração entre o CEP, o método de solução de problemas e o FMEA. Finalmente, explora-se a integração entre todos os métodos, conjuntamente.

\section{O QFD, o FMEA e a integração entre eles}

O QFD foi um método criado para operacionalizar o processo de planejamento da qualidade. 
Ele consiste em uma série de relações causa e efeito operacionalizadas por meio de matrizes. Em cada ciclo do QFD se relaciona as necessidades da qualidade (o que se espera) com os requisitos da qualidade (como se pretende fazer) identificando-se, na matriz de relações, a intensidade do relacionamento entre eles (figura 2).

A intensidade do relacionamento é representada por símbolos de relações. Cada símbolo tem um peso numérico representando esta intensidade. A importância relativa (figura 2, à direita) é uma classificação (priorização) de cada necessidade da qualidade (o que se espera). Essas necessidades são ponderadas segundo o grau de importância para o cliente, atribuindo-se a cada necessidade um valor numérico. $\mathrm{Na}$ parte superior da figura (triângulo) identificam-se os relacionamentos entre os requisitos da qualidade (matriz de correlações). Estes relacionamentos identificam o grau de correlação entre os requisitos da qualidade, auxiliando na priorização e identificação de "soluções de compromisso" entre os requisitos. As especificações do projeto (quanto) representam uma quantificação de cada requisito da qualidade (como se pretende fazer). Os requisitos priorizados (retângulo abaixo) são calculados pela multiplicação do peso atribuído ao símbolo de relações (forte, moderado, fraco) pelo grau de importância relativa (BERK \& BERK, 1997).

Figura 2 - Representação simplificada do método QFD

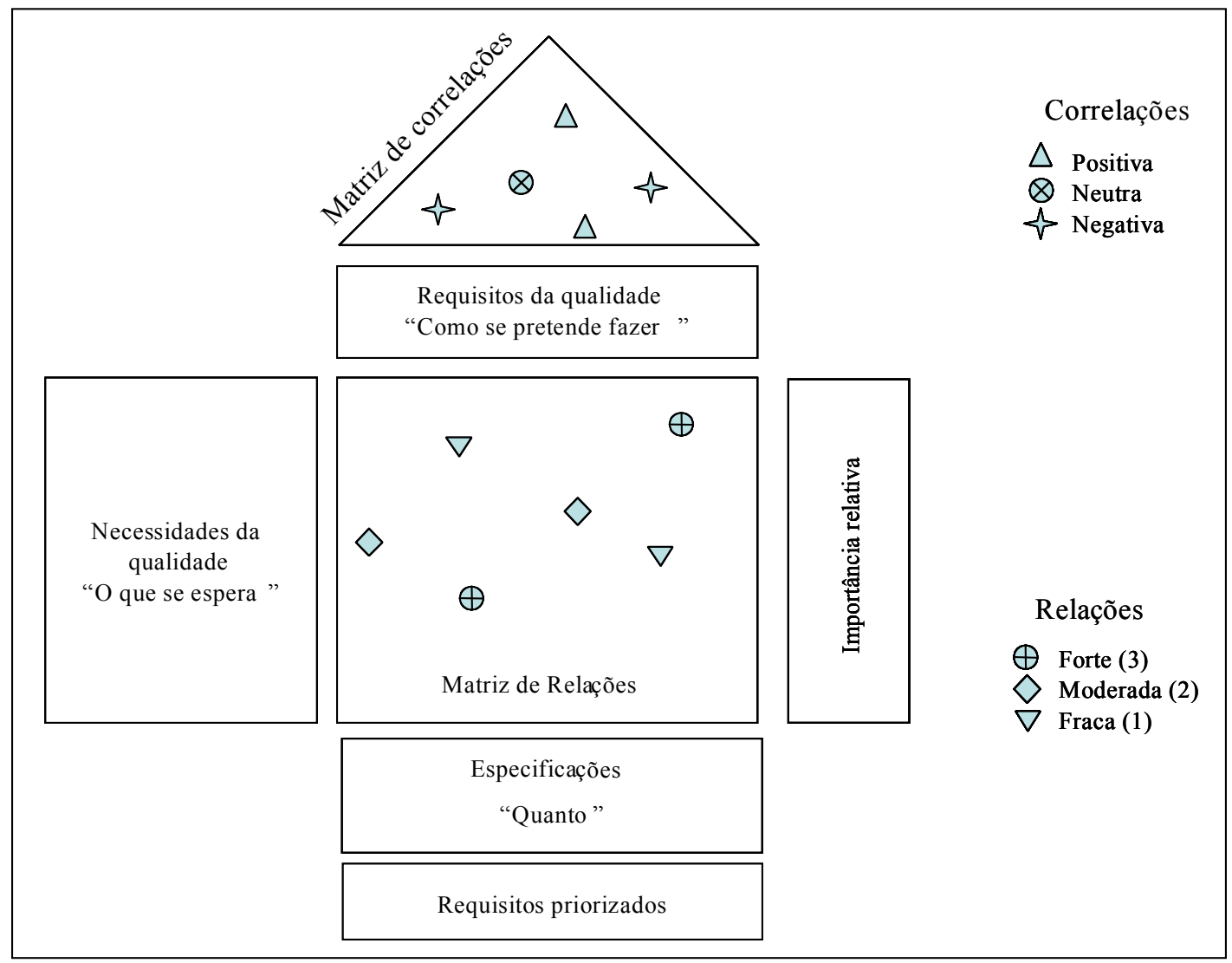

Fonte: adaptado de Berk \& Berk (1997, p.205)

Conforme a figura 3, o método QFD engloba quatro fases ou ciclos de relações causa efeito: desenvolvimento das necessidades dos clientes; projeto do produto e componentes; projeto 
do processo; controle do processo. Para cada uma dessas fases tem-se a execução dos desdobramentos e priorizações apontados acima (AKAO, 1990). De acordo com a figura, as expectativas dos clientes desdobram-se em necessidades dos clientes (ciclo 1), as quais geram as características do produto (ciclo 2). As características do produto desdobram-se, por sua vez, em características do processo (ciclo 3) e finalmente, as características do processo são traduzidas em necessidades de controle do processo (ciclo 4). As entradas, processamento e saídas do QFD são representados na figura 4.

Figura 3 - Os quatro ciclos do método QFD.

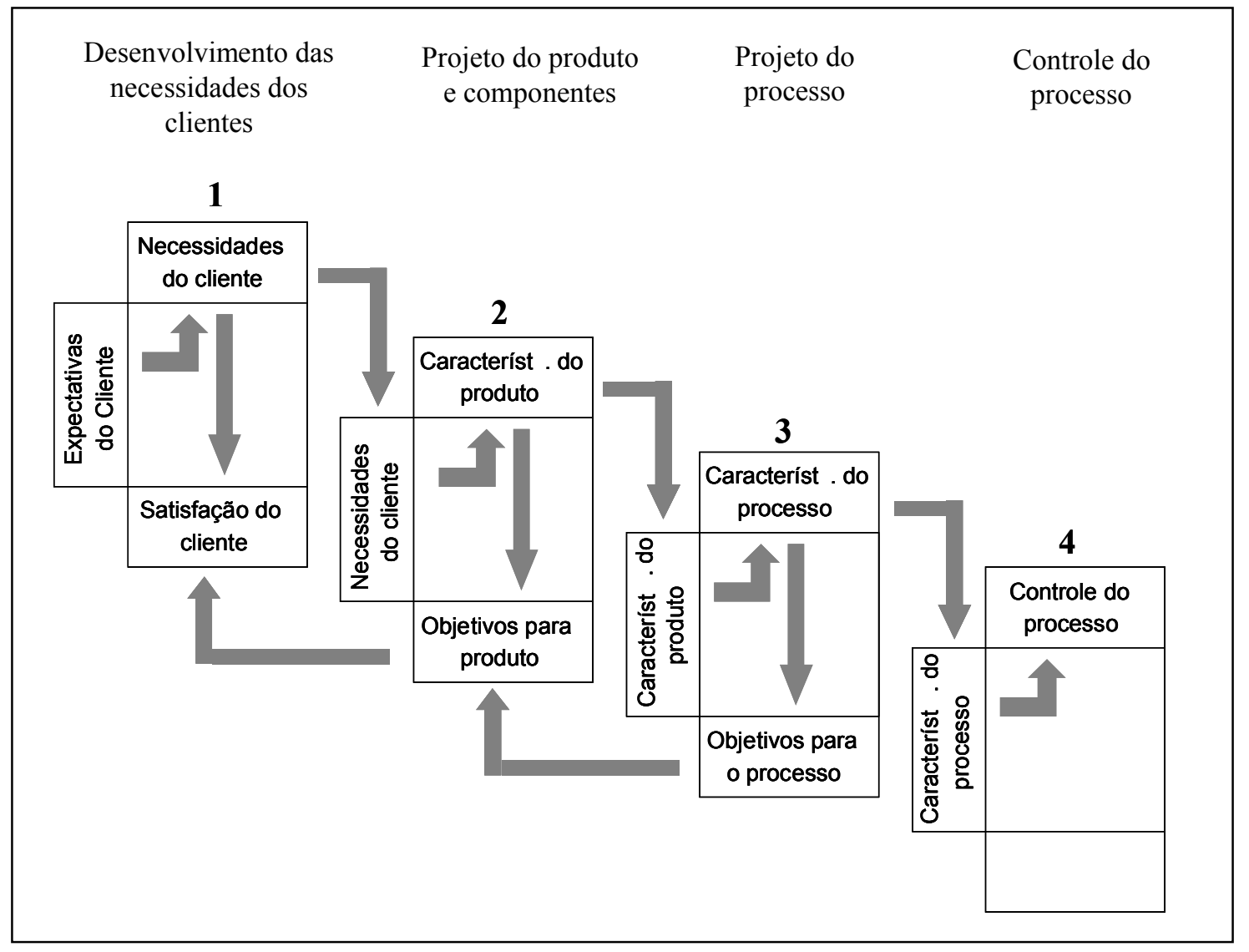

Figura 4 - Entradas, processamento e saídas do método QFD.

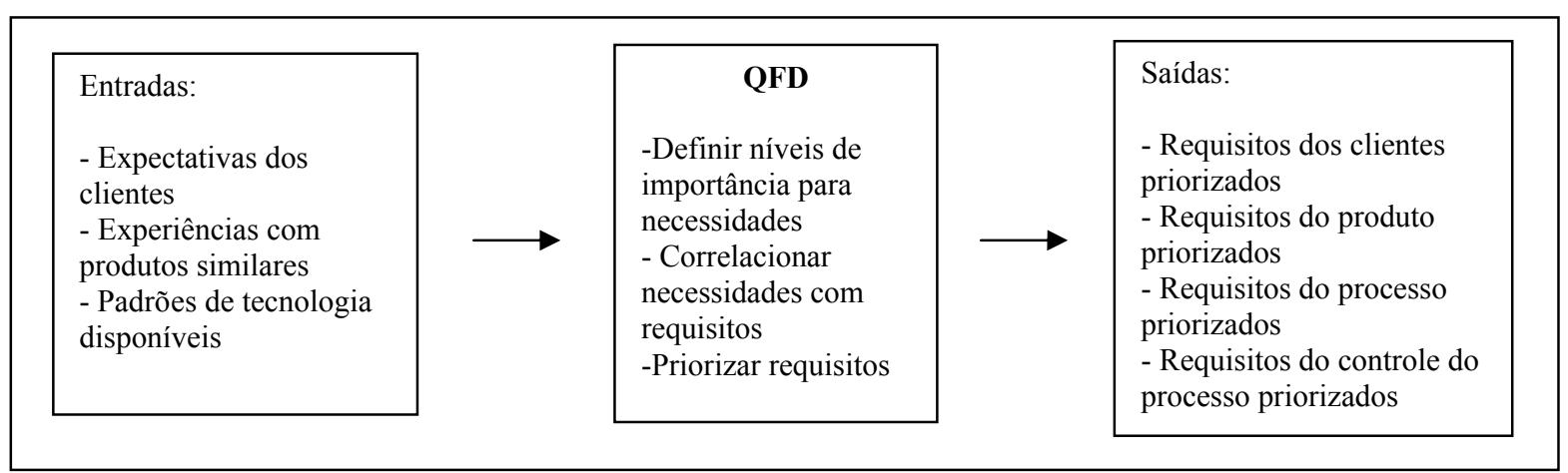

Conforme Puente (2002), o método FMEA é útil para identificar, de forma sistemática, falhas potenciais em sistemas e processos, identificar seus efeitos e definir ações que visem reduzir 
ou eliminar o risco associado a cada falha. O FMEA avalia a severidade de cada falha relativamente ao impacto causado aos clientes, a forma como estas podem ocorrer e, caso ocorram, como poderiam ser detectadas antes de chegarem às mãos dos clientes. Com base nestes três elementos, severidade, ocorrência e detecção, o FMEA leva à priorização de quais modos de falha levam aos maiores riscos ao cliente. As etapas para a execução de um FMEA são as seguintes:

a) Listar modos de falha conhecidos e potenciais;

b) Identificar os efeitos de cada modo de falha e a sua respectiva severidade;

c) Identificar as causas possíveis para cada modo de falha e a probabilidade de ocorrência de falhas relacionadas a cada causa;

d) Identificar o meio de detecção no caso da ocorrência do modo de falha e sua respectiva probabilidade de detecção;

e) Avaliar o potencial de risco de cada modo de falha e definir medidas de eliminação ou redução do risco de falha.

A eliminação ou redução dos riscos de falha é feita através de ações que aumentem a probabilidade de detecção ou reduzam a probabilidade de ocorrência da falha. A severidade é um índice que não pode ser reduzido ou eliminado, pois depende apenas do nível de transtorno que a falha trás ao cliente. A técnica utilizada para se determinar o risco associado a cada modo de falha (Risk Potential Number, RPN) é a multiplicação da pontuação dada para as classificações da severidade (S), da ocorrência (O) e da detecção (D). Com isto, tem-se uma escala que vai de 1 a 1000 pontos, sendo 1 um baixíssimo risco e 1000 um risco crítico ao cliente. Após a priorização dos riscos devem ser definidas medidas para a redução ou eliminação dos maiores riscos calculados. $\mathrm{Na}$ figura 5 observa-se um típico formulário para execução de um FMEA.

Figura 5 - Exemplo de formulário do FMEA

\begin{tabular}{|c|c|c|c|c|c|c|c|c|c|c|c|c|c|c|}
\hline \multirow[b]{2}{*}{ Função } & \multirow[b]{2}{*}{$\begin{array}{l}\text { Modo de } \\
\text { Falha }\end{array}$} & \multirow[b]{2}{*}{ Efeito } & \multirow[b]{2}{*}{ 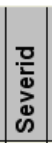 } & \multirow[b]{2}{*}{ Causa } & \multirow[b]{2}{*}{$\begin{array}{l}2 \\
0 \\
0 \\
0\end{array}$} & \multirow[b]{2}{*}{$\begin{array}{l}\text { Controle } \\
\text { atuais }\end{array}$} & \multirow[b]{2}{*}{ 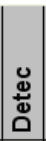 } & \multirow[b]{2}{*}{$\frac{\alpha}{2}$} & \multirow[b]{2}{*}{ Ações recomendadas } & \multicolumn{5}{|c|}{ Resultados das ações } \\
\hline & & & & & & & & & & $\begin{array}{l}\text { Ações } \\
\text { tomadas }\end{array}$ & 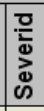 & 늠 & 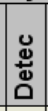 & $\frac{\alpha}{\frac{\alpha}{n}}$ \\
\hline Baixo custo & Alto custo & $\begin{array}{l}\text { Prejudica vendas } \\
\text { devida a queda na } \\
\text { satisfação do cliente }\end{array}$ & 8 & $\begin{array}{l}\text { Previsâo incorreta } \\
\text { devido a variação no } \\
\text { mercado }\end{array}$ & 4 & $\begin{array}{l}\text { Avaliçẫo de } \\
\text { custos }\end{array}$ & 3 & 96 & $\begin{array}{l}\text { Efetuar pesquisa mais } \\
\text { abrangente }\end{array}$ & & & & & \\
\hline \multirow[t]{2}{*}{$\begin{array}{l}\text { Iluminaçẩo } \\
\text { agradável }\end{array}$} & \multirow[t]{2}{*}{$\begin{array}{l}\text { lluminação } \\
\text { nẩo } \\
\text { agradável }\end{array}$} & \multirow[t]{2}{*}{$\begin{array}{l}\text { Prejudica vendas } \\
\text { devida a queda na } \\
\text { satisfaçẫo do cliente }\end{array}$} & \multirow[t]{2}{*}{7} & \multirow[t]{2}{*}{$\begin{array}{l}\text { Tipo atual de } \\
\text { resistências e gases } \\
\text { só permitem } \\
\text { iluminaçăo limitada }\end{array}$} & \multirow[t]{2}{*}{4} & \multirow[t]{2}{*}{ Nenhum } & \multirow[t]{2}{*}{10} & \multirow[t]{2}{*}{280} & $\begin{array}{l}\text { Pesquisar projetos } \\
\text { alternativos e novas } \\
\text { pesquisas na área }\end{array}$ & & & & & \\
\hline & & & & & & & & & $\begin{array}{l}\text { Pesquisar junto aos } \\
\text { clientes o que é } \\
\text { iluminação agradável }\end{array}$ & & & & & \\
\hline
\end{tabular}

Segundo Stamatis (2003), existem diversos tipos de FMEAs. Dentre eles destacam-se: FMEA de sistema; FMEA de produto; e FMEA de processo. O FMEA de sistema (FMEA de 
conceito) é utilizado para avaliar as falhas em sistemas e subsistemas nos estágios iniciais de definição de conceituação e projeto (mas também deve ser reaplicado durante toda a vida útil do sistema). Ele enfoca falhas potenciais do sistema em relação à execução das suas funcionalidades e em atender às necessidades dos clientes, ou seja, está diretamente ligado à percepção do cliente em relação ao sistema. O FMEA de produto (FMEA de projeto) é utilizado para avaliar possíveis falhas em produtos antes da sua liberação para a manufatura (mas deve ser reutilizado durante toda a vida útil do produto). Ele enfoca falhas potenciais do projeto em relação ao cumprimento dos objetivos definidos para cada uma de suas características e está diretamente ligado à capacidade do projeto em atender os objetivos pré-definidos. O FMEA de produto define necessidade de alterações no projeto do produto, estabelece prioridades para as ações de melhoria no projeto, auxilia na definição de testes e validação do produto, na identificação de características críticas e significativas do produto e na avaliação dos requisitos e alternativas do projeto. O FMEA de processo é utilizado para avaliar as falhas em processos antes da sua liberação para produção (mas deve ser reaplicado durante toda a vida do processo). Ele enfoca falhas potenciais do processo em relação ao cumprimento dos objetivos pré-definidos para cada uma de suas características e está diretamente ligado à capacidade do processo em cumprir esses objetivos. O FMEA de processo define necessidades de alterações no processo, estabelece prioridades para as ações de melhoria, auxilia na execução do plano de controle do processo e na análise dos processos de manufatura e montagem.

$\mathrm{Na}$ figura 6 são identificados os quatro ciclos do método QFD e a localização da aplicação dos FMEAs de sistema, produto e processo que podem se integrar a cada um destes ciclos. $\mathrm{Na}$ figura 7 representam-se as entradas, processamento e saídas do método FMEA.

Notadamente, tanto o QFD quanto o FMEA visam verificar a percepção do cliente em relação às funções do produto. Ambos os métodos usam relações causa-efeito, ambos prevêem a priorização das funções críticas ao cliente e ambos requerem um time multifuncional para serem executados. Porém, enquanto o QFD enfoca a satisfação e o desempenho do produto em relação ao cliente, o FMEA, por sua vez, enfoca a análise dos riscos potenciais de falha de cada função do produto (ou do processo ou do sistema), ou seja, ele objetiva manter as qualidades básicas do produto, visando atingir o nível esperado de qualidade.

As saídas básicas do QFD são os requisitos priorizados. Tanto requisitos do cliente, do produto, do processo e do controle, ou seja, para cada ciclo do QFD tem-se uma priorização dos requisitos, como resultado (TERNINKO, 1997). Por outro lado, o FMEA tem como entrada os requisitos do cliente, do produto e do processo e informações sobre a importância relativa de cada uma das funções (PALADY, 1997). Assim, afirma Stamatis (2003), a melhor maneira para se obter as entradas do FMEA é utilizando as saídas do QFD. Na figura 8, representa-se graficamente a interface entre o QFD e o FMEA com as respectivas entradas e saídas. Observa-se na figura que 
todas as saídas do QFD alimentam o FMEA.

Figura 6 - Aplicação do FMEA integrada a cada ciclo do QFD.

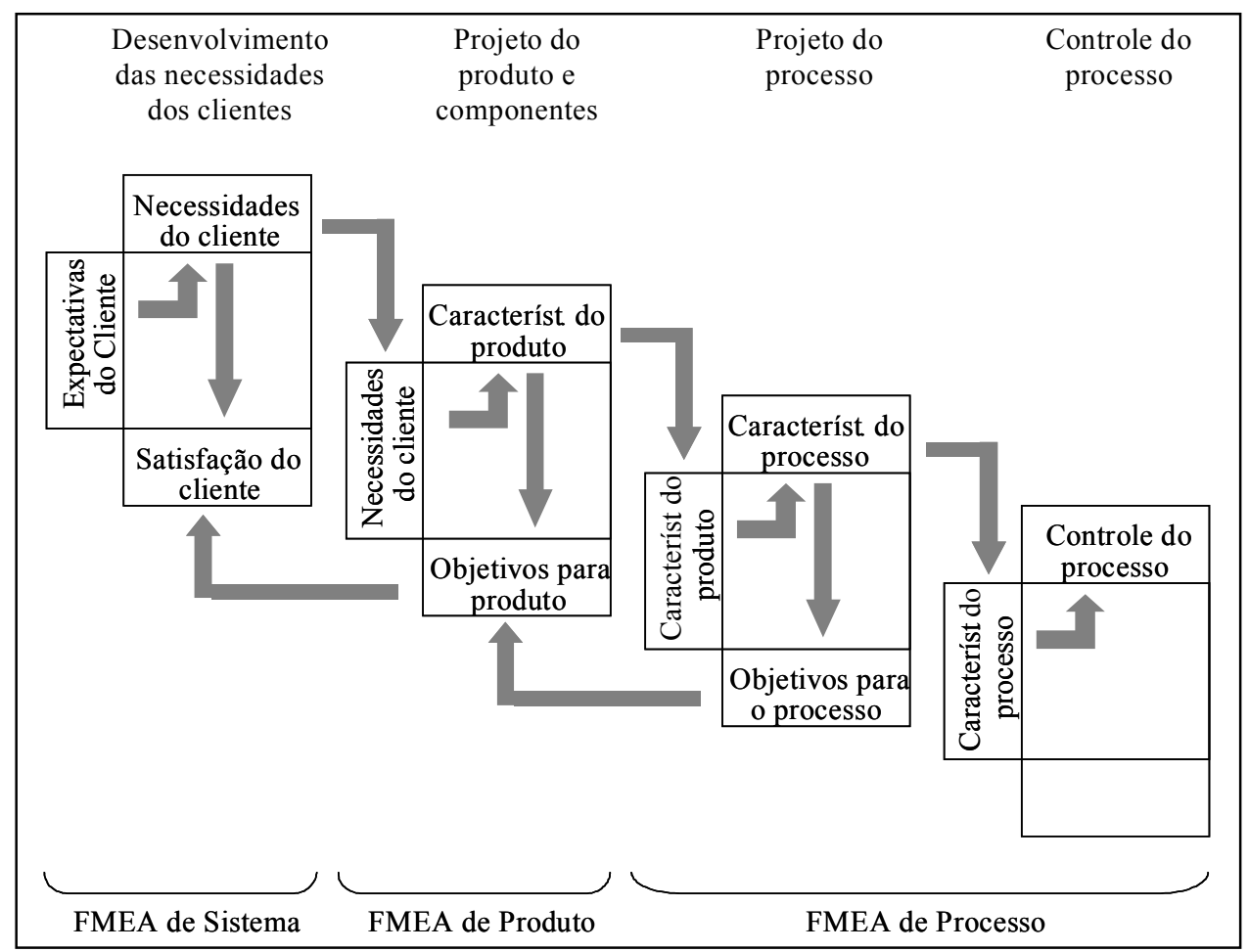

Figura 7. Entradas, processamento e saídas do método FMEA.

Entradas:

- Requisitos dos clientes, dos produtos, dos processos e do controle de processos

- Informações históricas de falhas e confiabilidade

- Informações atuais de falhas ou modificações nos sistemas, produtos ou processos

\section{FMEA}

- Descrever modos de falhas, efeitos, causas, meios de prevenção e de detecção

- Classificar a

severidade, a

ocorrência e a detecção dos modos de falhas e suas causas

- Priorizar e definir ações que

minimizem ou

eliminem os riscos de falhas
Saídas:

- Modos de falhas

priorizados conforme o

risco ao cliente

- Meios de detecção e

prevenção dos modos de falha

- Ações para minimizar os riscos de falhas 
Figura 8. Interface QFD/FMEA

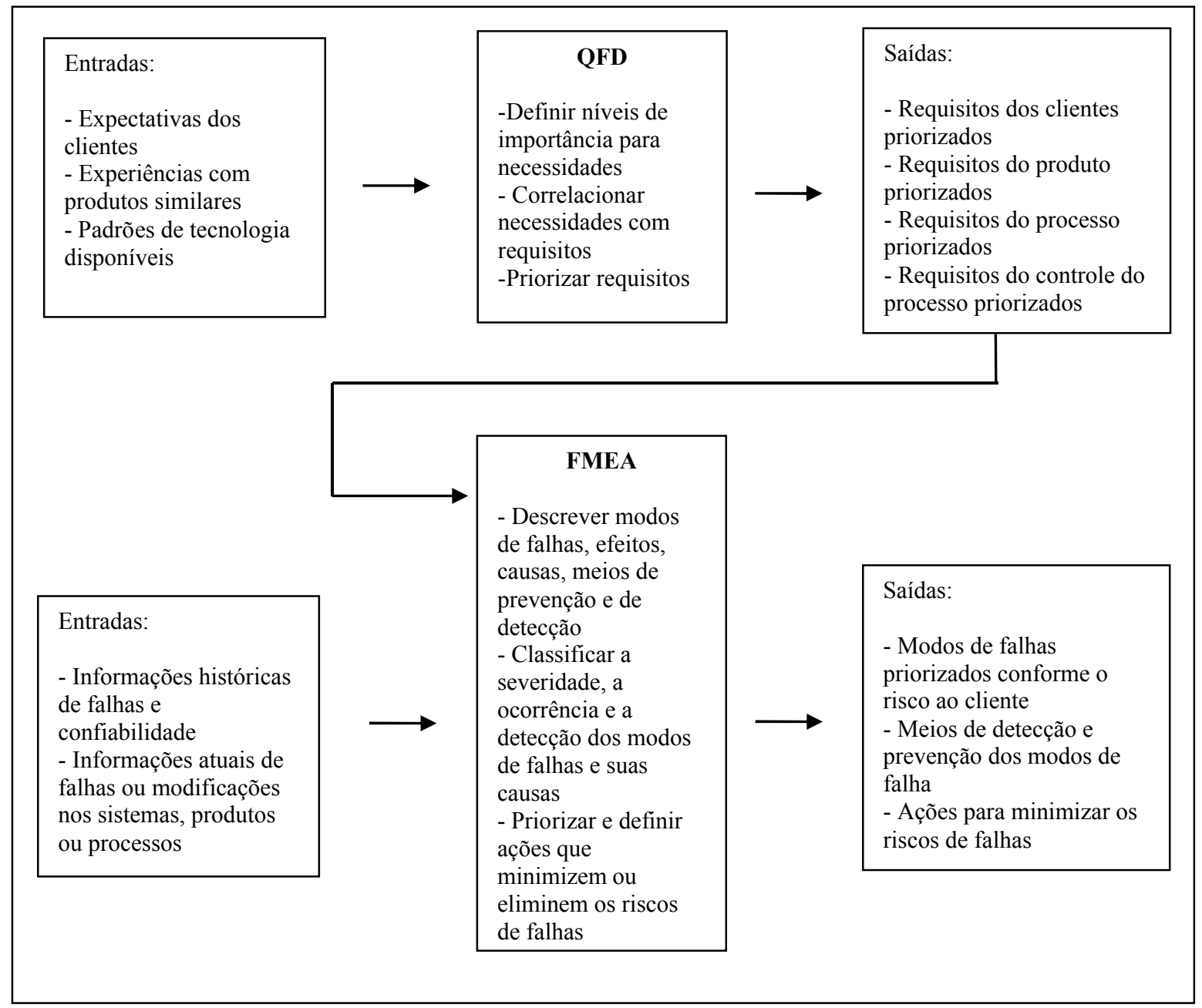

\section{O PQP e sua integração com o FMEA}

O PQP é um método utilizado para definir, em um único documento, todas as informações necessárias ao processo de controle da qualidade (ISO/TS 16949, 2002). No PQP constam as seguintes informações (CHRYSLER et al, 1998):

a) Etapas do processo;

b) Características do produto ou do processo a ser controlada (requisitos do processo);

c) Meios de controle (instrumentos ou equipamentos de medição);

d) Métodos de controle (seqüência operacional para o controle);

e) Freqüência de medição;

f) Tamanho da amostra;

g) Limites de especificação;

h) Identificação das características críticas;

i) Plano de reação em caso de desvios $\mathrm{Na}$ figura 9 representam-se as entradas, o processamento e as saídas do método PQP. 
Figura 9. Entradas, processamento e saídas do método PQP.

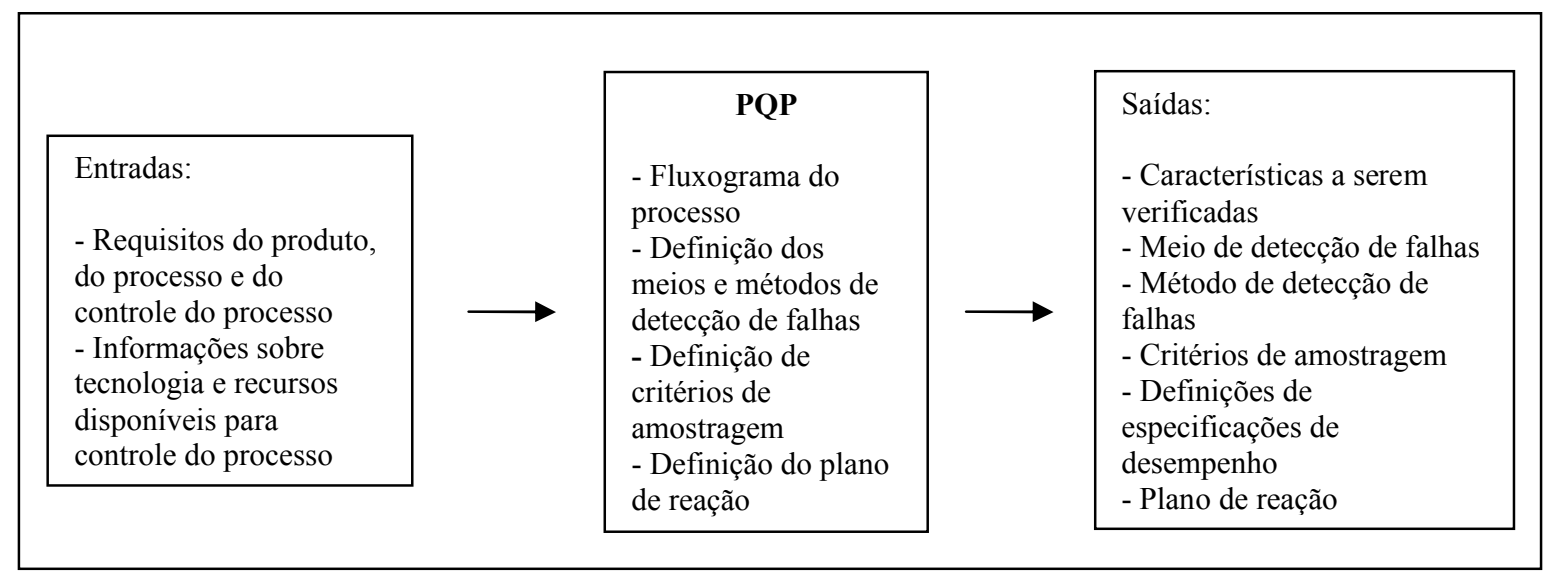

O meio, o método, a freqüência e o tamanho da amostra no controle do processo são formas de garantir a detecção de falhas no processo produtivo. Sendo assim, afetam a avaliação do nível de detecção do FMEA de processo. Com isto, nota-se que algumas informações constantes no PQP devem também constar no FMEA de processo. Desta forma, os processos PQP e FMEA são naturalmente inter-relacionados. Na figura 10 representa-se a inter-relação entre estes dois métodos.

Figura 10 - Interface FMEA/PQP

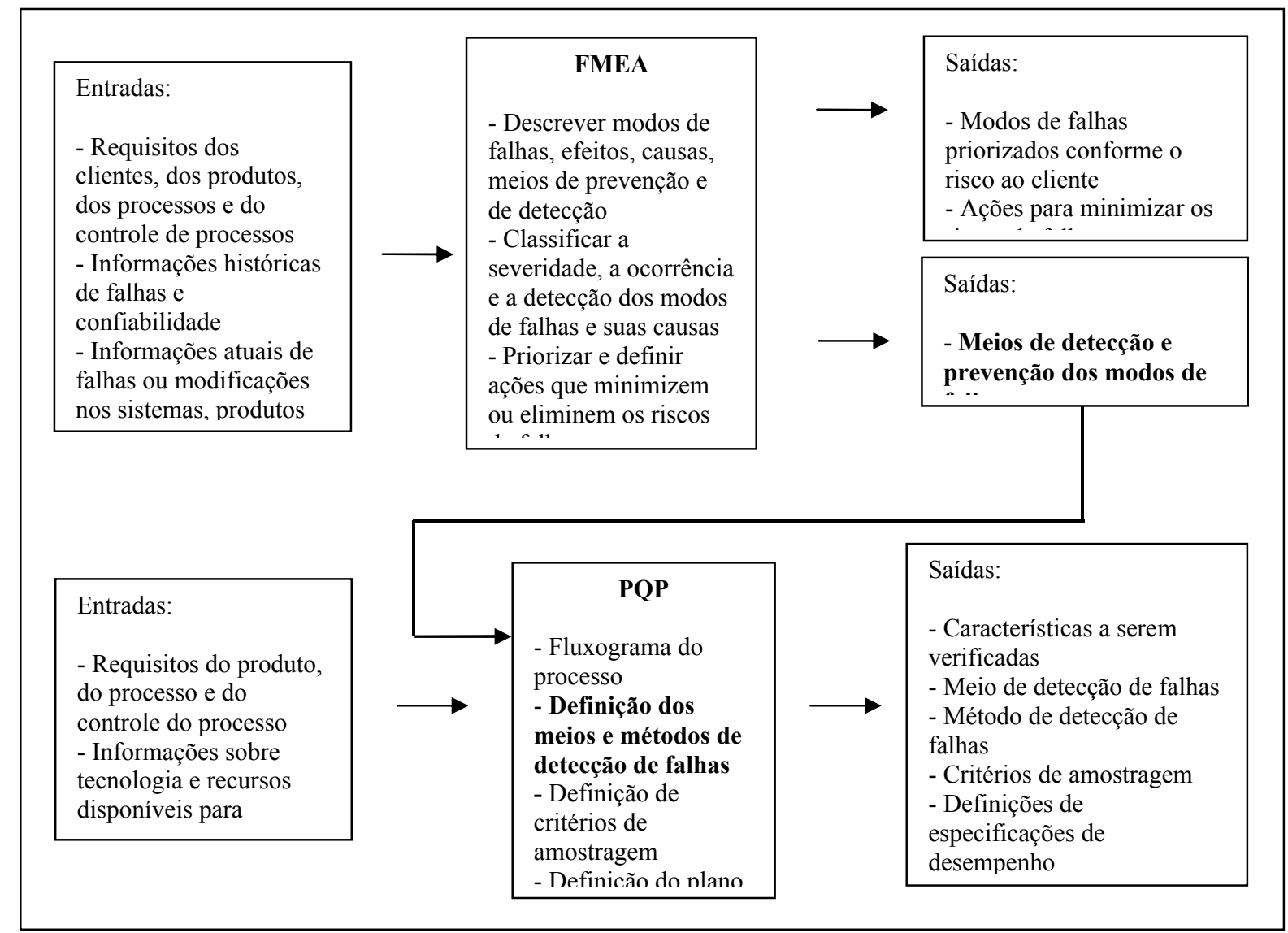

Pode-se observar por esta figura que nem todas as saídas do FMEA alimentam o PQP (apenas as saídas do retângulo inferior). Essas saídas estão destacadas em negrito, pois elas 
constituem numa parte do processamento do próprio PQP, também destacadas em negrito, o que economiza trabalho na execução do PQP.

\section{As inspeções, as auditorias de produto e sua integração com o PQP e o FMEA}

A inspeção do produto é um método de detecção de defeitos que se faz medindo-se uma característica do produto e comparando-a com seu padrão de projeto (PALADINI, 2002). As auditorias de produto são feitas da mesma forma. Porém, diferem-se das inspeções pelo fato das inspeções condicionarem a liberação do lote ao resultado destas, o que não acontece com as auditorias, cujo resultado é somente utilizado como um indicador para tomada de ações corretivas no processo (FERNANDES, 2005). A figura 11 apresenta as entradas, o processamento e as saídas das inspeções e auditorias de produto.

O PQP gera informações de balizamento tanto para as inspeções quanto para as auditorias de produto. As inspeções e auditorias de produto, por sua vez, alimentam o FMEA com informações sobre falhas detectadas para que estas possam ser analisadas em detalhe. Na figura 12 representa-se as inter-relações entre o PQP, as inspeções, as auditorias de produto e o FMEA. Na figura evidencia-se (em retângulos distintos) as saídas do PQP que são entradas para as inspeções e auditorias de produto de as saídas das inspeções e auditorias de produtos que são entradas para o FMEA.

Figura 11. Entradas, processamento e saídas das inspeções e auditorias de produto.

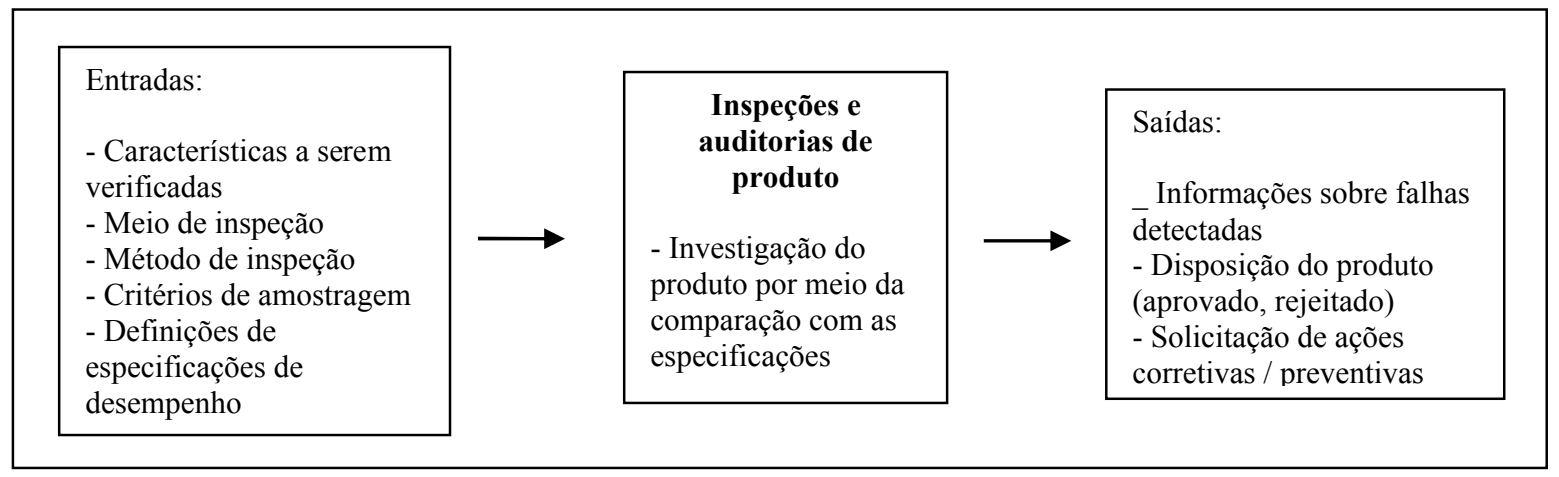

\section{O CEP, o método de solução de problemas e a sua integração com o FMEA}

Um fenômeno interessante detectado na gestão da qualidade é o da degradação da eficiência nas inspeções. Este fenômeno ocorre porque as inspeções não são 100\% precisas, pois os inspetores falham com alta freqüência. Por exemplo, uma inspeção $100 \%$ é $80 \%$ precisa. Com isto, um em cada cinco defeitos será enviado ao cliente e isto se agrava em inspeções por amostragem (CRAIG, 2004). Para tornar a inspeção mais eficaz e para não se ter que utilizar amostragem $100 \%$ foi criado, 
por Shewhart, o CEP (SHEWHART, 1986). Quando a organização tem exigências próximas a zero defeito, não é recomendável confiar apenas na precisão da inspeção para garantir a qualidade. Porém, com o CEP, o zero defeito passa a ser factível.

Figura 12. Interfaces entre o PQP, as inspeções, as auditorias de produto e o FMEA.

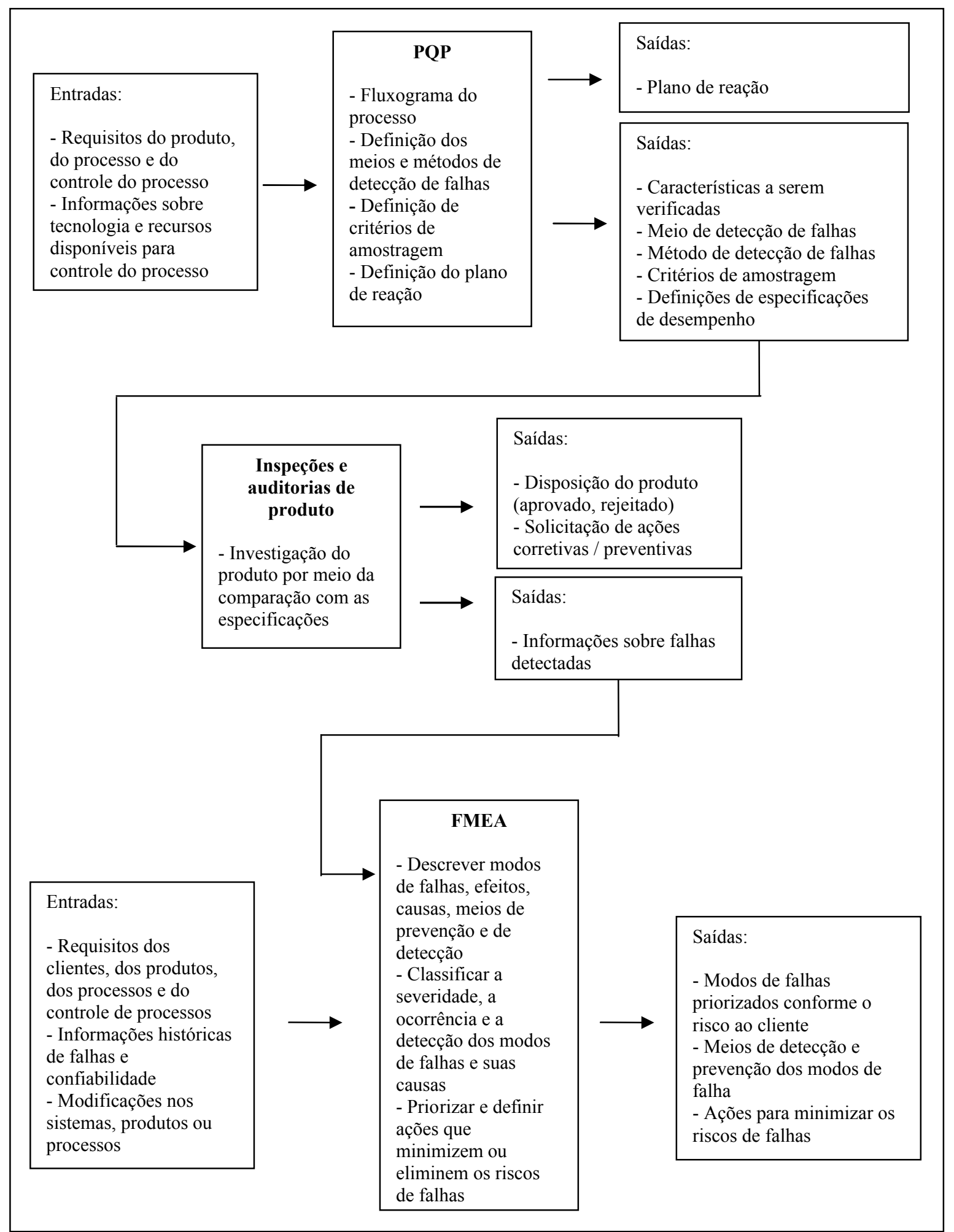

O CEP utiliza o gráfico de controle para distinguir a variabilidade aleatória da não- 
aleatória. A base do gráfico de controle é a distribuição amostral, que tende a ter a curva de probabilidades associada numa distribuição gaussiana.

O gráfico de controle tem dois limites - calculados a partir dos dados amostrais - que separam a variação aleatória da variação não-aleatória. $O$ valor maior é o limite superior de controle (LSC), e o valor menor é o limite inferior de controle (LIC). Uma estatística amostral que cair entre esses dois limites sugere a aleatoriedade da distribuição, enquanto um valor exterior a um dos dois limites sugere a não-aleatoriedade.

No CEP é comum a utilização do LSC três sigmas acima da linha média e do LIC três sigmas abaixo desta. O CEP é um método de detecção das causas assinaláveis, ou seja, causas incomuns que, agindo no processo, provocam alta variabilidade na saída. Por meio do gráfico de controle, avaliam-se tendências, padrões de não-aleatoriedade e instabilidades do processo, permitindo a sua interrupção e a ação corretiva antes que se produzam itens fora dos limites de especificação (figura 13).

Figura 13. Exemplo de gráfico de controle.

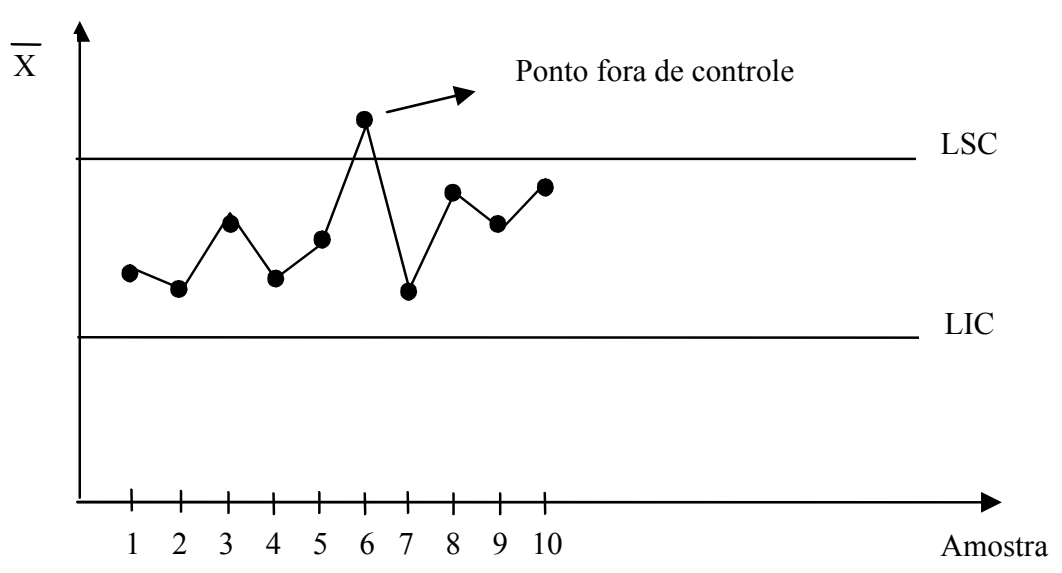

Além disso, o CEP permite o cálculo de índices de capabilidade do processo. Estes índices avaliam a variabilidade intrínseca do processo relativamente à variação permitida pelas especificações de projeto. Se esta variabilidade estiver dentro das especificações, diz-se que o processo é capaz. Caso contrário o processo será incapaz e, sem uma intervenção visando reduzir sua variabilidade natural, ele não produziria conforme as especificações previstas no projeto (MONTGOMERY, 1997). A figura 14 mostra o CEP com suas entradas e saídas. 
Figura 14. Entradas, processamento e saídas do CEP.

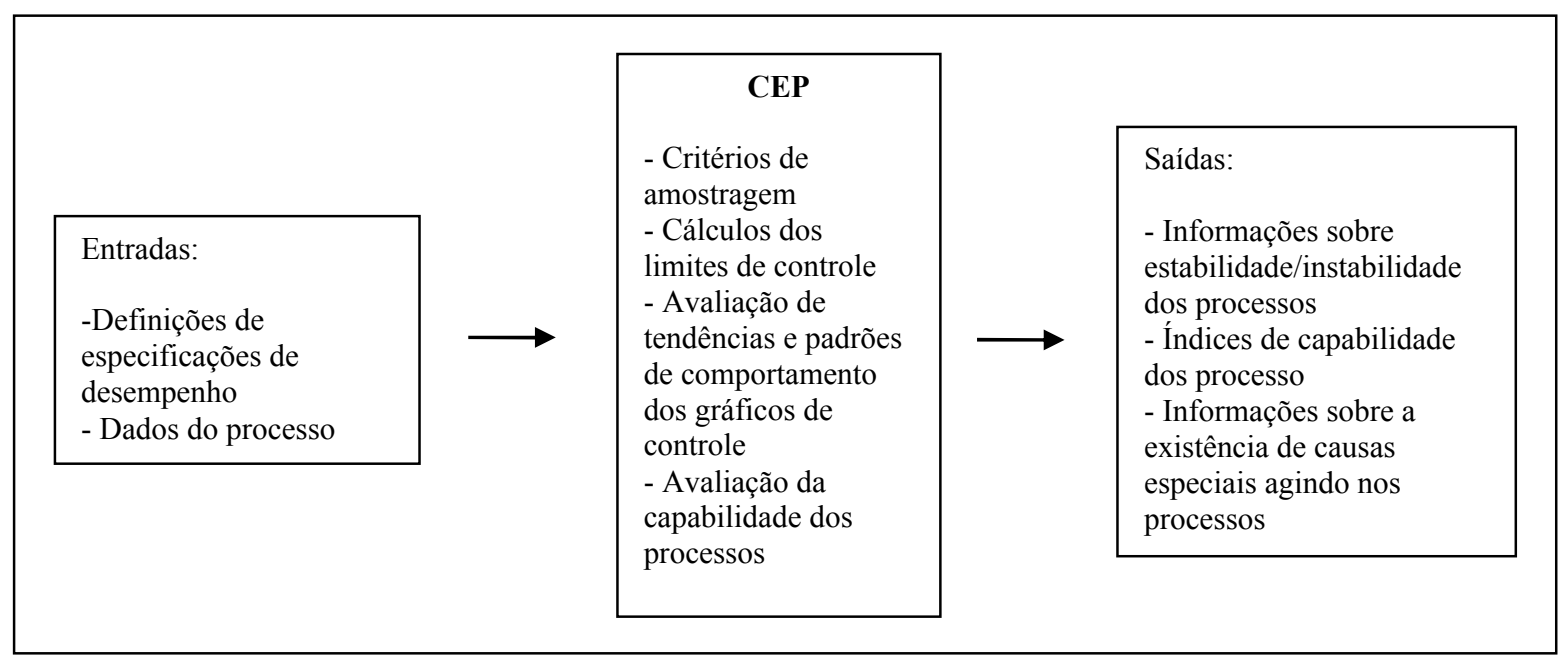

O último passo dentro do controle da qualidade é a tomada de ações para corrigir os desvios em relação aos objetivos e, aqui, para que a ações não se percam, é muito importante o uso de um método sistemático (FASSER \& BRETTNER, 2002). São muitos os métodos disponíveis, cada um deles têm suas particularidades, mas essencialmente seguem os mesmos passos principais. O método QC Story foi aqui selecionado como ilustração dada a sua popularidade entre especialistas e empresas. Segundo este método, um problema deve ser resolvido conforme as seguintes etapas (KUME, 1993):

a) Definição do problema. Nesta etapa apresenta-se o histórico do problema, a perda do desempenho na atual situação, quanto o desempenho deveria ser melhorado, fixa-se uma meta e apresenta-se um orçamento e um cronograma estimado para a melhoria.

b) Observação. Consiste em investigar o problema a partir de vários pontos de vista sobre quatro elementos de ocorrência: tempo, local, tipo e efeito;

c) Análise. Nesta etapa se estabelecem hipóteses causais e testam-se estas hipóteses;

d) Ação. Aqui, seleciona-se um conjunto de ações, examinam-se as vantagens e desvantagens de cada uma e elege-se aquela com a qual o pessoal envolvido estiver de acordo;

e) Verificação. Consiste em comparar os dados antes e depois da execução das ações, converter os efeitos em valores monetários, e comparar o resultado da implementação com o valor-alvo;

f) Padronização. Nesta etapa coloca-se em prática, por meio da comunicação necessária, a solução encontrada na forma de uma nova conduta de trabalho;

g) Conclusão. Consiste em revisar o processo de resolução de problemas e planejar o trabalho futuro para atacar novos problemas. 
Com a execução do CEP pode-se identificar a presença de caudas especiais (nãoaleatórias) agindo no processo produtivo. Normalmente, o próprio responsável pelo processo (operador) se encarrega de pesquisar, identificar e corrigir as causas especiais que estão tirando o processo de controle. Porém, se o problema não for identificado ou apresentar causas de difícil resolução para o operador, a empresa deve acionar uma equipe para executar o método de solução de problemas.

No processo de execução do FMEA são definidas medidas para redução dos maiores riscos (RPN) no processo produtivo. Estas medidas são ações para reduzir a ocorrência ou melhorar a detecção de um determinado modo de falha. Para implementação destas ações, pode-se utilizar uma ferramenta para a solução de problemas, como o método QC Story, cujas entradas e saídas estão representadas na figura 15.

Figura 15. Entradas, processamento e saídas do método de solução de problemas.

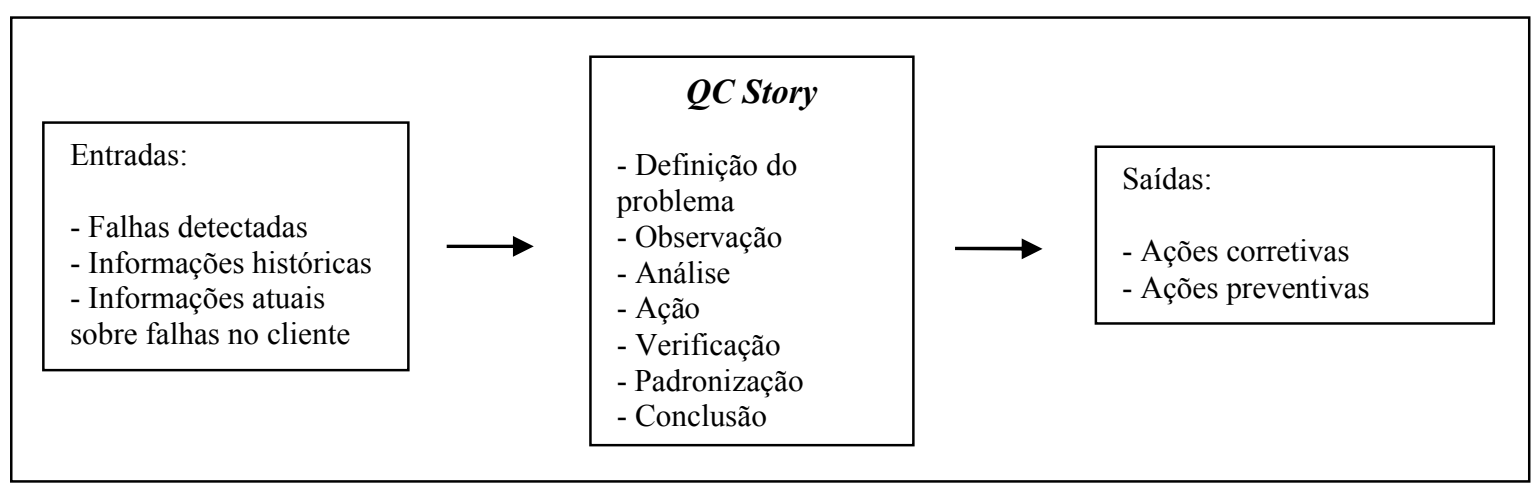

Desta forma, é possível utilizar o método de solução de problemas não somente corretivamente, mas também preventivamente, atuando nos riscos apontados pelo FMEA de forma a tomar ações definitivas que garantam a diminuição destes riscos. Após a utilização da metodologia de solução de problemas as ações resultantes devem constar no FMEA, que deve ser atualizado conforme a nova situação do processo. Esta inter-relação fecha um ciclo entre a metodologia de solução de problemas e o FMEA (figura 16). 
Figura 16. Interfaces entre o CEP, o método de solução de problemas QC Story e o FMEA.

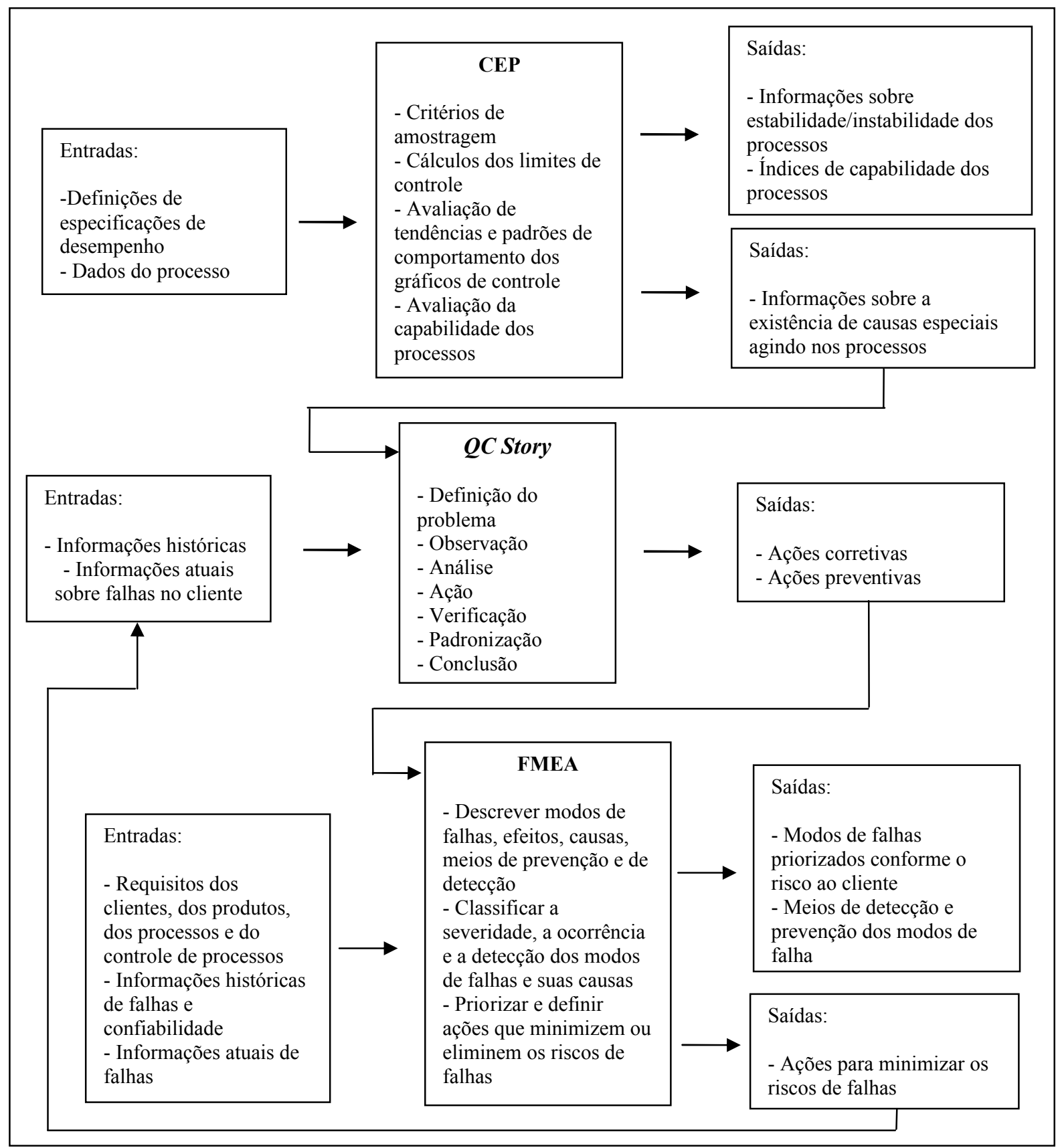

\section{A integração entre os métodos}

As inter-relações entre todos os métodos estão representadas na figura 17. A figura apresenta três regiões divididas por duas linhas verticais tracejadas: entradas externas, representando as informações que alimentam todo o processamento integrado e que não são geradas pelos métodos destacados, podendo ser internas ou externas à empresa; processamento integrado, que a partir das entradas externas gera as saídas; saídas externas, que contêm os resultados do processamento integrado. 
Figura 17. Integração entre todos os métodos destacados

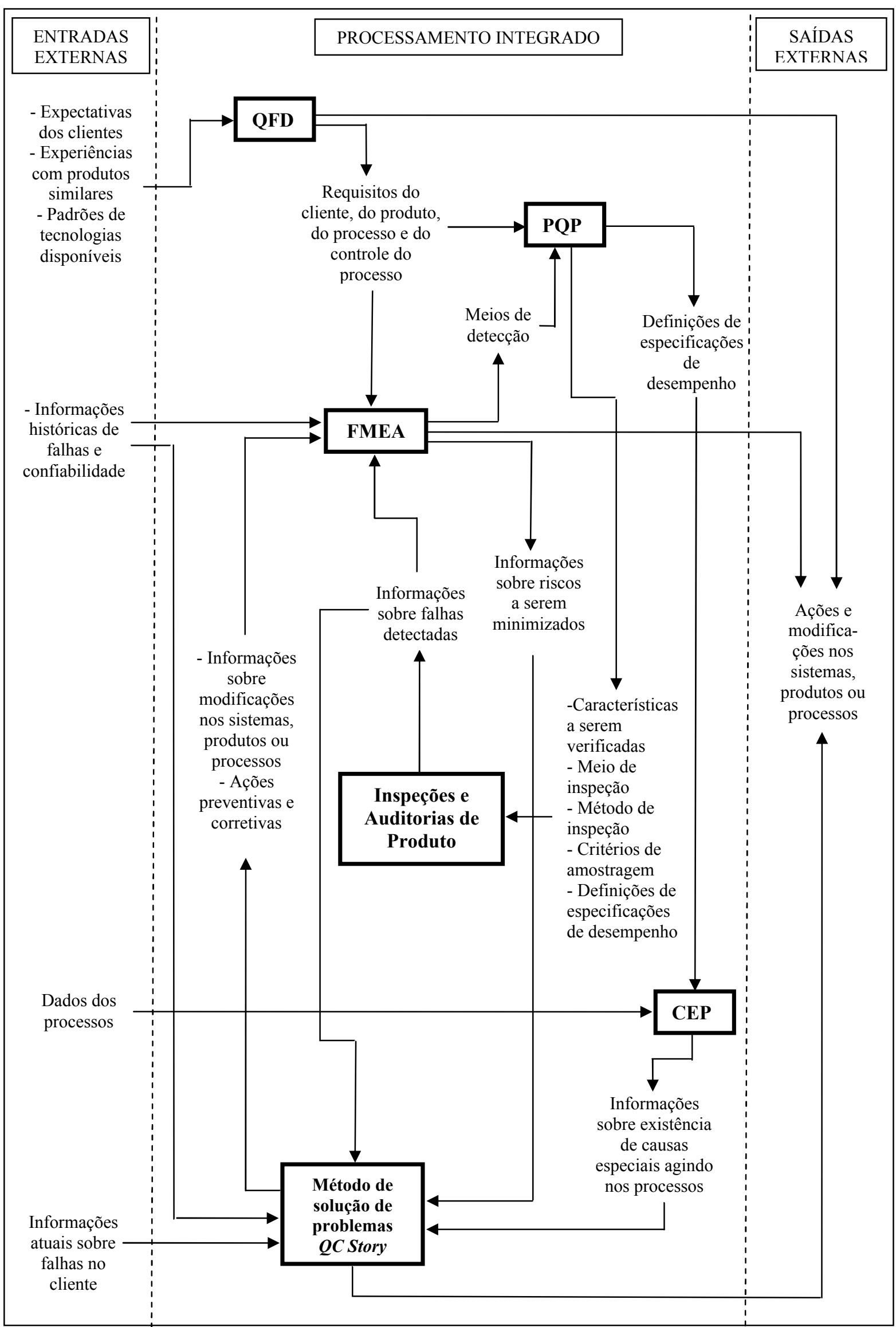

O planejamento da qualidade se inicia com a utilização do método QFD. O QFD tem como entrada (entrada externa) as expectativas dos clientes, as experiências com produtos similares e 
padrões de tecnologia disponíveis. Por meio de seus quatro ciclos em sucessão, o QFD desdobra as expectativas do cliente em requisitos (em ordem de prioridade) do cliente, do produto, do processo e do controle do processo (para evitar a sobrecarga da figura, este detalhe não é mostrado). Ainda no planejamento da qualidade, o método FMEA é utilizado para avaliar riscos dos requisitos - do cliente, do produto, do processo e do controle do processo - falharem em atender seus objetivos. Dessa forma, a priorização resultante do QFD é utilizada para alimentar a análise da severidade dos modos de falhas nos FMEAs de sistema, projeto e processo (este detalhe também não é mostrado na figura). O FMEA também utiliza como entrada as informações históricas de falhas e confiabilidade de sistemas, produtos e processos (entradas externas). Estas informações são úteis para se estimar, por meio do FMEA, os índices de ocorrência dos modos de falha.

O FMEA alimenta o PQP, primeiro método de controle da qualidade a ser destacado, através da saída "meios de detecção". Os meios de detecção são importantes para o FMEA porque afetam os níveis de risco calculados para cada modo de falha. Desta forma, uma das formas de se reduzir estes níveis de riscos de falha é modificar (incrementar), por meio do FMEA, os meios de detecção.

O PQP se integra ao QFD na medida em este último define os requisitos do produto, do processo e do controle do processo, informações que devem alimentar o plano de controle. O PQP também se integra ao segundo processo de controle da qualidade, o CEP. O PQP define em quais processos deve ser aplicado o CEP. Também alimenta o CEP com as definições das especificações de desempenho. Estas definições permitem que o CEP avalie a capabilidade dos processos. Convém observar neste ponto que a definição do tamanho da amostra e freqüência de amostragem especificamente para o CEP são geradas "nele mesmo", ou seja, não vêm de outro método. Isto porque estes critérios são dependentes dos "níveis de controle desejados", já que o tamanho da amostra influencia os limites de controle.

O PQP também alimenta as inspeções e auditorias de produto, terceiro e quarto métodos dentro do controle da qualidade. As definições das especificações de desempenho, características a serem verificadas, meio de detecção, método de detecção, critérios de amostragem (freqüência de amostragem e tamanho da amostra) são informações "saídas" do PQP que alimentam as inspeções e auditorias de produto. As saídas das inspeções e auditorias de produto (informações sobre falhas detectadas) são usadas para alimentar dois métodos. Por um lado, elas retro-alimentam o FMEA, e neste caso, servem para revisões em FMEAs de processo. Por outro lado, alimentam o método de solução de problemas (quinto e último método do controle da qualidade) para que se dê início às investigações de falhas e à tomada de ações corretivas.

O método de solução de problemas também tem como entradas as informações históricas de falhas e informações atuais sobre falhas no cliente, ambas entradas externas. As informações sobre falhas no cliente podem ser geradas pelo departamento assistência técnica da empresa, por exemplo. 
Outra entrada para o método de solução de problemas é uma das saídas do FMEA, as informações sobre riscos a serem minimizados. O método de solução de problemas deverá minimizar ou eliminar estes riscos por meio da ação sobre as causas, de modo a se reduzir a probabilidade de ocorrência das falhas potenciais. Dessa forma, uma das saídas do método de solução de problemas é retro-alimentada ao FMEA para que este seja revisto, recalculando e re-avaliando o nível de risco de falha a partir das mudanças efetivadas. Estas saídas são destacadas na figura como "informações sobre modificações nos sistemas, produtos ou processos e ações preventivas e corretivas".

Outra entrada do método de solução de problemas são as informações advindas do CEP. O CEP tem como sua principal saída informações sobre a existência de causas especiais agindo nos processos e gerando descontrole. Estas informações direcionam o método de solução de problemas na identificação, investigação e tomada de ações corretivas. O CEP, porém, precisa de dados do processo (entrada externa), que na forma de "medições amostrais" dos produtos produzidos irá estimar a variabilidade, os limites de controle e acompanhar a evolução destes dados por meio dos gráficos de controle.

Pela figura 17, observa-se que as saídas externas do processamento integrado são geradas exclusivamente pelo QFD, pelo FMEA ou pelo método de solução de problemas. Estas saídas são destacadas como "ações e modificações nos sistemas, produtos ou processos", representado o ponto de convergência e de interesse de todo o trabalho realizado por meio do processamento integrado: ajustar os processos com o objetivo de produzir produtos que se alinhem, da maneira mais perfeita possível, às expectativas dos clientes.

\section{Conclusões}

Os diferentes métodos voltados ao planejamento e controle da qualidade disponíveis aos gestores, se por um lado se mostram eficazes na obtenção de seus objetivos, por outro lado são tratados de forma individual. Sem a integração entre os métodos, o gerenciamento da qualidade tenderá a ser um processo fragmentado, incompleto e pouco eficiente. Os métodos, do modo como foram originalmente propostos, carecem de interfaces com outros métodos.

A abordagem integrativa aqui proposta vem de encontro a essa carência gerencial, na medida em que identifica e explora as possibilidades de entrelaçamento entre os métodos destacados. Curiosamente, a "abordagem por processos" emergiu naturalmente dentro da proposta integrativa. Ao visualizar a abordagem completa, sente-se que perde o sentido pensar a qualidade de maneira segmentada, isto é, em planejamento da qualidade e controle da qualidade. É claro que estes são dois construtos abstratos importantes para se "refletir sobre todo o processo" didaticamente e também como recurso taxionômico de entendimento. Porém, na gestão da 
qualidade aplicada, o que interessa é o processamento das entradas em saídas de forma sucessiva, completa e contínua.

Talvez seja incoerente afirmar que existe algum método que possa ser eleito como o mais importante. Se qualquer um dos métodos fosse suprimido, o resultado do processamento integrado ficaria prejudicado. Porém, a abordagem integrativa evidencia a importância do método FMEA neste esquema proposto. Pela figura 17, pode-se verificar que o FMEA é o método que contém o maior número de entradas e saídas, dentre todos os métodos destacados. O FMEA é o único método que atua efetivamente em falhas potenciais, e é o único método que analisa três elementos importantíssimos para o sistema produtivo: o prejuízo que a falha pode causar, a possibilidade de ocorrência da falha e como esta falha pode ser detectada antes que o produto chegue ao cliente. Deste modo, o FMEA oferece à abordagem integrada um caráter preventivo que, excluindo-se o método de solução de problemas, os outros métodos não são capazes de oferecer.

O segundo método que mais apresenta entradas e saídas na abordagem proposta é o método de solução de problemas. Ele é o método de correção efetiva de irregularidades. Além disso, ao agir sobre causas potenciais de falhas, indicadas, porém, pelo FMEA, ele auxilia na prevenção de problemas.

Os métodos QFD, FMEA e de solução de problemas são os únicos métodos que interferem diretamente nos processos, ou seja, que produzem ações originais ou modificações efetivas nos sistemas, produtos e processos (saídas do processamento integrado). Desta forma, podem ser classificados como "métodos fim". Os métodos PQP, inspeções, auditorias de produto e CEP, são métodos voltados ao monitoramento e controle da qualidade, não são métodos "de ação", são métodos de apoio aos métodos fim, e por isso, podem ser chamados de "métodos meio".

A abordagem proposta pode integrar-se completamente à "trilogia" de Juran - planejamento da qualidade, controle da qualidade e melhoria contínua - (JURAN, 2000) por meio da incorporação da melhoria contínua. A melhoria contínua pode ser efetivada, através da abordagem proposta, em três estágios de melhoria previstos por Shiba et al (1997): melhoria "de controle", melhoria "reativa" e melhoria "proativa". É preciso entender, porém, que a melhoria contínua não constitui um novo método a ser incorporado, e sim formas distintas de aplicação da abordagem integrada.

Quando a abordagem integrada estiver sendo executada com vistas a corrigir pequenos erros ou falhas, isto é, atuando sobre o sistema produtivo para que os processos voltem aos padrões operacionais previamente definidos, o processamento integrado estará agindo na melhoria de controle. Ao aplicar-se a abordagem integrativa em processos originalmente ruins (processos incapazes) com vistas à melhoria desses processos em termos da redução de sua variabilidade, o enfoque da melhoria contínua será o de melhoria reativa (reação a problemas maiores). De outra forma, a abordagem integrativa pode ser utilizada na prospecção de problemas potenciais no tocante 
ao atendimento das expectativas dos clientes, o que obviamente, tem uma abrangência de ação muito mais ampla. Este tipo de melhoria será classificado como melhoria proativa.

A abordagem integrativa foi pensada para ambientes de manufatura, não para ambientes de prestação de serviços. Métodos como o CEP, inspeções e auditorias de produtos não se mostram adequados à aplicação nos serviços, especialmente nas "funções de frente" (front-office functions). Já para as funções de retaguarda (back-room functions), crê-se que haja a possibilidade de aplicação da abordagem integrada desde que adequações ao sistema de fornecimento sejam executadas.

\begin{abstract}
In the current days, the majority of the organizations that applies the different methods directed to the quality management are not able to understand how they can work in integrated way. The continuity and integration lack in the application of the quality methods difficult the managemental action and the companies who do not work to repair this gap operate, inevitably, a fragmented management. This article has the objective to identify and to explore the integration between methods directed to the planning and to the control of the quality. It was selected, from specialized literature, the following methods inside of each cited area: Quality Function Deployment (QFD) and Failure Mode and Effect Analysis (FMEA) in the planning of the quality; Process Quality Plan (PQP), Inspections, Product Audit, Statistical Process Control (SPC) and QC Story Method - as a method of problems solution - in the control of quality.
\end{abstract}

Key-words: quality planning; quality control; quality methods integration.

\title{
Referências
}

AKAO, Y. Quality Function Deployment: integrating customer requirements into product design. Cambridge: Productivity Press USA, 1990.

AUTOMOBILINDUSTRIE, Verband der VDA 6.1. Gerenciamento do Sistema da Qualidade na Indústria Automobilística: Auditoria do Sistema da Qualidade. São Paulo: IQA - Instituto da Qualidade Automotiva, 1998.

BERK, J.; BERK, S. Administração da qualidade total: o aperfeiçoamento contínuo. São Paulo: IBRASA, 1997.

CERVO, A. L.; BERVIAN, P. A. Metodologia científica. 5. ed. São Paulo: Prentice Hall, 2002.

CHRYSLER CORPORATION; FORD MOTOR COMPANY; GENERAL MOTORS CORPORATION. Requisitos do Sistema da Qualidade QS-9000. São Paulo: IQA - Instituto da Qualidade Automotiva, 1998.

CRAIG, D. J. Stop depending on inspection. Quality Progress, Chicago, v.37, n.7, p.39-50, July 2004.

CROSBY, P. B. Qualidade é investimento. 6. ed. Rio de Janeiro: J. Olympio, 1994.

FASSER, Y.; BRETTNER, D. Management for quality in high-technology enterprises. 1 Ed. New York: WileyInterscience, 2002.

FERNANDES, J. M. Uma proposta de integração entre métodos para o planejamento e controle da qualidade. Curitiba: PUCPR, 2005, 145p. Dissertação (Mestrado) - Programa de Pós-Graduação em Engenharia de Produção e Sistemas, Curitiba, 2005.

ISO 9001: 2000. Requisitos do Sistema da Qualidade ISO 9001. São Paulo: IQA - Instituto da Qualidade Automotiva, 2000.

ISO/TS 16949. Quality systems - automotive suppliers - particular requirements for the application of ISO 9001:2000 for automotive production and relevant service part organizations. International Organization for 
Standardization, Switzerland, 2002.

JURAN, J. M. Juran`s Quality Handbook. 5. Ed. New York: McGraw-Hill, 2000.

KELLER, C. W. QOS - A simpple method for a big or small. Quality Progress, Chicago, v.36, n. 9, p.28-39, July 2003.

KUME, H. Métodos estatísticos para melhoria da qualidade. São Paulo: Gente, 1993

MONTGOMERY, D. C. Introduction to statistical quality control. 3rd ed. New York: J. Wiley \& Sons, 1997.

MOURA, E. As sete ferramentas gerenciais da qualidade: implementando a melhoria contínua com maior eficácia. São Paulo: Makron, 1994.

PALADINI, E. P. Avaliação estratégica da qualidade. São Paulo: Atlas, 2002.

PALADY, P. FMEA - Análise de Modos de Falhas e Efeitos: prevendo e prevenindo problemas antes que ocorram. São Paulo: IMAM, 1997.

PUENTE, J.; PINO, R.; PRIORE, P., FOUENTE, D. A decision support system for applying failure mode and effects analysis. International Journal of Quality \& Reliability Management, Bradford, v.19, n.2, p.137-151, 2002.

cross ${ }^{\text {ref }}$

SHEWHART, W. A. Statistical method from the viewpoint of quality control. New York: Dover Publications, 1986.

SHIBA, S.; GRAHAM, A.; WALDEN, D. TQM: quatro revoluções na gestão da qualidade. Porto Alegre: Artes Médias, 1997.

STAMATIS, D.H. Failure Mode and Effect Analysis: FMEA from theory to execution. 2. Ed. ASQ, Milwaukee: Quality Press, 2003.

TERNINKO, J. Step-by-step QFD: customer-driven product design. Boca Raton: CRC Press, 1997.

\section{Nome completo: Macelo Giroto Rebelato}

Filiação institucional: Unesp Campus Jaboticabal

Departamento: Economia Rural

Função ou cargo ocupado: Professor Dr.

Endereço completo para correspondência (bairro, cidade, estado, país e CEP): Av. Cap. Alberto Mendes Jr - 542 - 14887-008 - Jaboticabal / SP

Telefones para contato: (16) 3202-8141 ou (16) 8163-9828

\section{e-mail: mgiroto@fcav.unesp.br}

\section{Nome completo: José Marcio Ramos Fernandes}

Filiação institucional: Robert Bosch Brasil

Departamento: Gestão da Qualidade

Função ou cargo ocupado: Engenheiro da qualidade

Endereço completo para correspondência (bairro, cidade, estado, país e CEP): Av. Juscelino Kubitschek de Oliveira, no 11800 Cidade Industrial - Curitiba / PR - CEP 81450-902 
e-mail: Jose.Fernandes@br.bosch.com

Nome completo: Andréia Marize Rodrigues

Filiação institucional: Unesp Campus Jaboticabal

Departamento: Economia Rural

Função ou cargo ocupado: Professora Dra.

Endereço completo para correspondência (bairro, cidade, estado, país e CEP): Via de Acesso Prof.

Paulo Donato Castellane, s/n - Zona Rural - Jaboticabal / SP - CEP 14884-900

Telefones para contato: (16) 3202-2635 - Ramal 202

e-mail: andreiamarize@fcav.unesp.br 